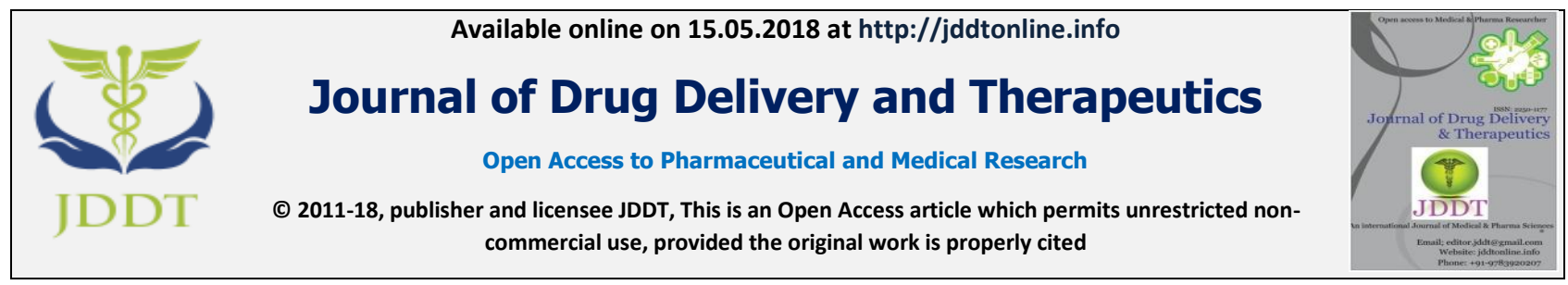

Open Access

Research Article

\title{
DESIGN AND CHARACTERIZATION OF DONEPEZIL HYDROCHLORIDE SUSTAINED RELEASE MATRIX TABLETS
}

\author{
Patel Kunal N*, Patel Sarthi S, Trivedi Harsh J, Patel Bhavana A, Patel Madhabhai M \\ Department of Pharmaceutics, Shree Swaminarayan Sanskar Pharmacy College, Gandhinagar, Gujarat, India
}

\begin{abstract}
The ultimate aim of the present study was to develop sustained release (SR) tablets of Donepezil Hydrochloride by employing natural polymers (Guar gum and Xanthan gum) as the matrix material in different proportion by wet granulation method. Initially drug-excipients compatibility studies were carried out using FTIR and DSC which showed no interaction between drug and excipients. Granules of prepared batches were evaluated for bulk density, tapped density, carr's index, hausner's ratio, angle of repose. Tablets were evaluated for various physicochemical parameters like hardness, thickness, friability, weight variation test, drug content and in vitro drug release. All the formulation showed compliance with pharmacopoeial standards. $3^{2}$ full factorial design was applied in which Guar gum $\left(\mathrm{X}_{1}\right)$ and Xanthan gum $\left(\mathrm{X}_{2}\right)$ were taken as independent factor and \%CDR at $2 \mathrm{hr}\left(\mathrm{Y}_{1}\right)$ and at $12 \mathrm{hr}\left(\mathrm{Y}_{2}\right)$ were taken as response. In-vitro drug release study revealed that as the amount of polymers increased, \% CDR decreased. Contour plots as well as response surface plots were constructed to show the effect of $X_{1}$ and $X_{2}$ on \%CDR and predicted at the concentration of independent variables $X_{1}(40 \mathrm{mg})$ and $X_{2}(40 \mathrm{mg})$ for maximized response. The kinetic release treatment showed that korsmeyer peppas equation has shown of $\mathrm{r}^{2} 0.9517$ which was close to one indicating that the dissolution profile fits in Korsmeyer-Peppas model and the mechanism of drug release from these tablets was by non-fickian diffusion mechanism. The optimized batch was kept for stability study at $40 \pm 2{ }^{\circ} \mathrm{C} / 75 \pm 5 \% \mathrm{RH}$ for a period of 1 month according to ICH guidelines and found to be stable after 1 month of study.
\end{abstract}

Keywords: Sustained release matrix tablet, Donepezil hydrochloride, Guar gum, Xanthan gum, $3^{2}$ full factorial design.

Article Info: Received 15 March, 2018; Review Completed 25 April 2018; Accepted 27 April 2018; Available online 15 May 2018

\section{Cite this article as:}

Patel KN, Patel SS, Trivedi HJ, Patel BA, Patel MM, Design and characterization of donepezil hydrochloride sustained release matrix tablets, Journal of Drug Delivery and Therapeutics. 2018; 8(3):64-74

DOI: http://dx.doi.org/10.22270/jddt.v8i3.1769

*Address for Correspondence:

Dr Kunal N Patel, Associate Professor, Department of Pharmaceutics, Shree Swaminarayan Sanskar Pharmacy College, Gandhinagar, Gujarat, India

\section{INTRODUCTION}

Oral route is the oldest and convenient way for the administration of therapeutic agents because of low amount of therapy and ease of administration leads to greater level of patient compliance. Approximately 50\% of the drug products available in the market are administered orally and traditionally, oral drug administration has been the major route for drug delivery. Sustained release systems include any drug delivery system that achieves slow release of drug over an extend period of time. Sustained release dosage forms have been demonstrated to improve therapeutic efficiency by maintenance of a steady drug plasma concentration. The oral route of administration for sustained release systems has received greater attention because of more flexibility in dosage form design. So, sustained release dosage form is a dosage form that release one or more drugs continuously in a predetermined pattern for a fixed period of time, either systemically or to a specified target organ. Sustained release tablets are commonly taken only once or twice daily, compared with counterpart conventional forms that may have to take three or four times daily to achieve the same therapeutic effect. Sustained release products provide an immediate release of drug that promptly produces the desired therapeutic effect, followed by 
gradual release of additional amounts of drug to maintain this effect over a predetermined period. ${ }^{1,2}$

Donepezil hydrochloride (DH) is a second-generation cholinesterase inhibitor (ChEI), used for the treatment of Alziemer's disease (AD) having greater specificity for the brain acetyl cholinesterase enzyme (AchE). This compound characterized by a long plasma half-life (70 $\mathrm{hr})$ and a bioavailability of $100 \%$. Donepezil hydrochloride currently formulated as film-coated tablets of $5 \mathrm{mg}, 10 \mathrm{mg}, 23 \mathrm{mg}$ doses for once a day oral administration under trend name ARICEPT®. The immediate release of cholinesterase inhibitors results in a spike in the patient's blood plasma levels within 2 to 5 hours after administration of the drug. The most common adverse events from ARICEPT cholinomimetic effects include nausea, diarrhea, insomnia, vomiting, muscle cramps, fatigue, bradycardia, abdominal pain, and anorexia, resulting in a reduction of patient compliance. These undesirable effects are due to the initial spike in blood plasma levels. Therefore an initial therapeutic regimen is often recommended wherein donepezil is first introduced at low doses for several weeks followed by the gradual increase to the appropriate active dose for the patient. A sustained release formulation may be advantageous in reducing the undesirable side effects associated with the rapid increase in blood plasma concentration levels immediately after administration of the drug. Such sustained release formulations could provide a uniform and constant rate of release over an extended period of time, which may achieve a stable and desired blood level of donepezil without the initial spike in drug plasma level. ${ }^{3}$ Therefore, the aim of the investigation is to develop, optimize and characterize the sustain release tablet of Donepezil hydrochloride using natural polymers.

\section{MATERIALS AND METHODS}

Donepezil hydrochloride was obtained as a gift sample from West Coast Pharmaceutical Works Ltd. Ahmedabad, Gujarat. Guar gum, Xanthan gum and Starch were procured as a gift sample from Chemdyes Corporation, Rajkot, Gujarat. Lactose was obtained as a gift sample from Finar chemicals, Ahmedabad, Gujarat. Magnesium stearate and Talc were purchased from S. D. Fine Chemicals, Mumbai, India. All other chemicals were of analytical reagent grade.

\section{Drug-Excipients Compatibility Study by FTIR ${ }^{4}$}

The Fourier transform infrared spectrum was obtained using an FT-IR spectrometer. The Donepezil hydrochloride and mixture of drug with other excipients were previously ground and mixed thoroughly with potassium bromide, an infrared transparent matrix, at 1:1 (Sample: $\mathrm{KBr}$ ) ratio, respectively. The $\mathrm{KBr}$ discs were prepared by compressing the powders at a pressure of 5 tons for $5 \mathrm{~min}$ in a hydraulic press. Forty Scan were obtained at a resolution of $4 \mathrm{~cm}^{-1}$, from 4000 to $600 \mathrm{~cm}^{-1}$ at Aum Research lab.

\section{$3^{2}$ Full Factorial Design ${ }^{5,6}$}

A $3^{2}$ full factorial design was adopted and the amount of polymers, Guar gum $\left(\mathrm{X}_{1}\right)$ and Xanthan gum $\left(\mathrm{X}_{2}\right)$, were taken as independent variables and cumulative percentage drug release at $2 \mathrm{hr}\left(\mathrm{Y}_{1}\right)$, and $12 \mathrm{hr}\left(\mathrm{Y}_{2}\right)$ was taken as dependent variables as shown in Table 1 . The factors were studied at three levels $(-1,0,+1)$ indicating low, medium and high, respectively, as represented in Table 2. The statistical optimization procedure was performed with the help of optimization software like Design Expert 11.0.4.0 demo version (Stat- Ease Inc.). The software performs the multiple regression analysis (MRA), analysis of variance (ANOVA) and statistical optimization.

The use of regression analysis in $3^{2}$ full factorial design generates polynomial equations for different models, with interacting terms and regression coefficients, useful in evaluating the responses. The software generates two models, particularly, full model (non- significant terms included) and reduced model (excluding non- significant terms). In the full model study, the responses were analysed using the quadratic equation below:

$$
\mathrm{Y}=\mathrm{b}_{0}+\mathrm{b}_{1} \mathrm{X}_{1}+\mathrm{b}_{2} \mathrm{X}_{2}+\mathrm{b}_{12} \mathrm{X}_{1} \mathrm{X}_{2}+\mathrm{b}_{11} \mathrm{X}_{1}^{2}+\mathrm{b}_{22} \mathrm{X}_{2}^{2}
$$

where $\mathrm{Y}$ is the response evaluated, b0 is the arithmetic mean response of 9 runs and bi is the estimated coefficient of $\mathrm{Xi}$. The main effects $\left(\mathrm{X}_{1}\right.$ and $\left.\mathrm{X}_{2}\right)$ represent the average result of changing one factor at a time from its low to high value. The interaction term $\left(\mathrm{X}_{1} \mathrm{X}_{2}\right)$ shows how the response changes when two factors are simultaneously changed. The polynomial terms $\left(\mathrm{X}_{1}^{2}\right.$ and $\mathrm{X}_{2}^{2}$ ) were included to investigate nonlinearity. In the reduced model study, the non- significant terms in the quadratic equation are removed using backward regression procedure to generate a reduced model which is more important in studying the influence of factors on the responses evaluated. The value and sign of regression coefficient (bi) indicates the magnitude of influence of the particular term on the response. The regression coefficients give the average change in a response when the particular factor is changed by a unit, when all the other terms remain constant. A positive sign on the regression coefficient indicates the factor has a positive effect on the response and negative sign indicates a negative effect.

The software performs the individual analysis of responses and calculates the sum of squares (SS), mean square (MS), Fischer's ratio (F statistics) and $P$ value. The F statistics and $P$ value give the significance level of each term. The terms with a $P$ value less than 0.05 are considered significant at a level of significance $\alpha=0.05$.

Table 1: Selection of Independent and Dependent Variables

\begin{tabular}{|c|c|c|c|}
\hline \multicolumn{2}{|c|}{ Independent variables } & \multicolumn{2}{c|}{ Dependent variables } \\
\hline $\mathbf{X}_{\mathbf{1}}$ & $\mathbf{X}_{\mathbf{2}}$ & $\mathbf{Y}_{\mathbf{1}}$ & $\mathbf{Y}_{\mathbf{2}}$ \\
\hline Concentration of Guar gum $(\mathrm{mg})$ & Concentration of Xanthan gum $(\mathrm{mg})$ & $\%$ CDR at $2 \mathrm{hr}$ & $\%$ CDR at 12hr \\
\hline
\end{tabular}


Table 2: Selection of Levels for Independent Variables and Coding of Variable

\begin{tabular}{|c|c|c|c|}
\hline \multirow{2}{*}{ Levels } & \multirow{2}{*}{ Coded value } & \multicolumn{2}{|c|}{ Independent variables } \\
\cline { 3 - 4 } & & $\begin{array}{c}\text { Concentration of Guar gum (mg) } \\
\mathbf{X}_{\mathbf{1}}\end{array}$ & $\begin{array}{c}\text { Concentration of Xanthan gum (mg) } \\
\mathbf{X}_{\mathbf{2}}\end{array}$ \\
\hline Low & -1 & 40 & 40 \\
\hline Intermediate & 0 & 50 & 50 \\
\hline High & +1 & 60 & 60 \\
\hline
\end{tabular}

Table 3: Composition of Factorial Design Batches D1 to D9

\begin{tabular}{|c|c|c|c|c|c|c|c|c|c|}
\hline Ingredients (mg) & D1 & D2 & D3 & D4 & D5 & D6 & D7 & D8 & D9 \\
\hline Donepezil Hydrochlorie & 23 & 23 & 23 & 23 & 23 & 23 & 23 & 23 & 23 \\
\hline Guar Gum & 40 & 50 & 60 & 40 & 50 & 60 & 40 & 50 & 60 \\
\hline Xanthan gum & 40 & 40 & 40 & 50 & 50 & 50 & 60 & 60 & 60 \\
\hline Lactose & 139.5 & 129.5 & 119.5 & 129.5 & 119.5 & 109.5 & 119.5 & 109.5 & 99.5 \\
\hline Magnesium Stearate & 2.5 & 2.5 & 2.5 & 2.5 & 2.5 & 2.5 & 2.5 & 2.5 & 2.5 \\
\hline Talc & 5 & 5 & 5 & 5 & 5 & 5 & 5 & 5 & 5 \\
\hline Total Weight (mg/tablet) & $\mathbf{2 5 0}$ & $\mathbf{2 5 0}$ & $\mathbf{2 5 0}$ & $\mathbf{2 5 0}$ & $\mathbf{2 5 0}$ & $\mathbf{2 5 0}$ & $\mathbf{2 5 0}$ & $\mathbf{2 5 0}$ & $\mathbf{2 5 0}$ \\
\hline
\end{tabular}

To select matrix polymer, a comparative study was carried out. In preliminary trial batches, different concentrations of Guar gum and Xanthan gum were screened. Donepezil Hydrochloride and other excipients are weighed accurately, transferred in mortar and pestle and thoroughly mixed for $15 \mathrm{~min}$. The powder mixture was granulated with $10 \% \mathrm{w} / \mathrm{v}$ starch paste. The wet mass was passed through $10 \#$ sieve and granules were dried at $50^{\circ} \mathrm{C}$ for $30 \mathrm{~min}$. in hot air oven. The dried granules were passed through $20 \#$ sieve and lubricated with talc and magnesium stearate which was previously passed through $80 \#$ sieve. Tablets were compressed using $8 \mathrm{~mm}$ punch on 10 station rotary tablet punching machine (Karnavati Engineering). Composition of tablets is mentioned in Table 3. Hardness of the tablets was maintained between 5.0 to $6.0 \mathrm{Kg} / \mathrm{cm}^{2}$ and tablet weight at $250 \mathrm{mg}^{7}$

\section{Pre Compression Evaluations ${ }^{8,9}$}

The evaluation of Pre compression parameters such as Bulk density, Tapped density, Carr's index, Hausner's ratio and Angle of repose of the granules.

\section{Post Compression Evaluation}

The prepared tablets were evaluated for physical and chemical characteristics.

\section{Diameter $^{10}$}

Tablets of each batch were selected and measured for diameter using vernier caliper.

\section{Thickness $^{10}$}

The thickness of five randomly selected tablets was measured using vernier calipers. The extent to which the thickness of each tablet deviated from $\pm 5 \%$ of the standard value was determined.

\section{Weight Variation ${ }^{11}$}

Uniformity of the weight test as described in the IP/BP was followed. Twenty tablets were selected at random and average weight was determined. Then individual tablets were weighed and the individual weight was compared with the average weight. The percentage deviation was calculated and checked for weight variation. Using this procedure weight variation range of all batches of formulations was determined and recorded.

Percentage Deviation $=\frac{\text { Individual } W t-\text { Average } W t}{\text { Individual } \text { Weight }}$

Hardness $^{11}$

The hardness of the tablets was determined by diametric compression using a Monsanto Hardness tester. A tablet hardness of about $5-6 \mathrm{~kg} / \mathrm{cm}^{2}$ is considered adequate for mechanical stability. Determinations were made in triplicate. The mean values and standard deviation for each batch were calculated.

Friability $^{11}$

The friability of tablets was performed in a Roche Friabilator. Five tablets were weighed together and then placed in the chamber. The friabilator was operated for 100 revolutions and the tablets were subjected to the combined effects of abrasion and shock because the plastic chamber carrying the tablets drops them at a distance of six inches with every revolution. The tablets are then dusted and re-weighed.

$$
F=\frac{\text { Winitial }- \text { Wfinal }}{\text { Winitial }} \times 100
$$

\section{Drug Content ${ }^{4}$}

The drug content was carried out by weighing ten tablets from each batch and calculated the average weight. Then the tablets were triturated to get a fine powder. From the resulting triturate, powder was weighed accurately which was equivalent to $23 \mathrm{mg}$ of Donepezil hydrochloride and dissolved in $100 \mathrm{ml}$ volumetric flask containing $100 \mathrm{ml}$ of dissolution media and volume was made to $100 \mathrm{ml}$ with solvent. The volumetric flask was shaken using sonicator for $1 \mathrm{hr}$. and after suitable dilution with dissolution media, the drug content was determined using UV-Visible Spectrophotometer at 229 nm. 


\section{In-vitro Drug Release Study ${ }^{4}$}

Release of the prepared tablets was determined using U.S.P type II paddle type dissolution rate test apparatus (TDT-06P, Electrolab) using $900 \mathrm{ml}$ of $0.1 \mathrm{~N} \mathrm{HCl}$ medium for 120 minutes, then in phosphate buffer $\mathrm{pH}$ 6.8 medium for $12 \mathrm{hrs}$. as dissolution medium. The temperature of $37 \pm 1^{\circ} \mathrm{C}$ was maintained and paddle was adjusted at $25 \mathrm{rpm}$ throughout the experiment. Withdrawn not less than $5 \mathrm{ml}$ of the dissolution solution at $1,2,4,6,8,10,12,14 \mathrm{hr}$ time interval and were replaced with $5 \mathrm{ml}$ of fresh dissolution media after each withdrawal. Filtered each sample through a membrane filter with pore size of not more than $0.45 \mathrm{~mm}$. The samples were analyzed after appropriate dilution by UV spectrophotometer at $\lambda \max 229 \mathrm{~nm}$.

\section{Statistical Analysis ${ }^{5,6}$}

Statistical Analysis of the $3^{2}$ full factorial design batches was performed by multiple regression analysis using Microsoft excel. In this design 2 factors are evaluated, each at 3 levels, and experimental trials are performed at all 9 possible combinations. To evaluate the contribution of each factor with different levels to the response, the two-way analysis of variance (ANOVA) was performed using the Design Expert 11.0.4.0 (STAT - EASE) trial version software. To graphically demonstrate the influence of each factor on the response, the response surface plots, Normal plot of residual, TwoDimensional counter plot, 3-D graph, and overlay plot were generated using the Design Expert 11.0.4.0 (STAT - EASE) demo version software.

\section{Check point Analysis ${ }^{5,6}$}

A checkpoint analysis was performed to confirm the role of the derived polynomial equation and contour plots in predicting the responses. Values of independent variables were taken at 3 points and the theoretical values of $\% \mathrm{CDR}$ at $2 \mathrm{hr}$ and $\% \mathrm{CDR}$ at $12 \mathrm{hr}$ were calculated by substituting the values in the polynomial equation.

\section{Optimization of Formulation ${ }^{5,6}$}

The computation for optimized formulation was carried using software, Design Expert 11.0.4.0 (STAT EASE). The optimized formulation was obtained by applying constraints (goals) on dependent (response) and independent variables (factors). The models were evaluated in terms of statistically significant coefficients and $\mathrm{R}^{2}$ values. Various feasibility and grid searches were conducted to find the optimum parameters. Various 3D response surface graphs were provided by the Design Expert software. The optimized formulation factors were evaluated for various response properties.

\section{Curve Fitting Analysis ${ }^{12}$}

In order to describe the kinetics of drug release from sustained release formulation, various mathematical equations have been proposed namely, Zero order, First order, Higuchi model and Hixson-Crowell cube root law. To authenticate the release model, dissolution data can further be analyzed by Korsmeyer Peppas equation. The criteria for the selection of most suitable model were value of regression coefficient $\left(\mathrm{R}^{2}\right)$ nearer to 1 , smallest values of Residual sum of squares (SSR) and Akaike Information Criteria (AIC).

\section{Similarity and Dissimilarity Study ${ }^{4,12}$}

The similarity factor $f 2$ as defined by FDA and EMEA is a logarithmic reciprocal square root transformation of one plus the mean squared (the average sum of squares) differences of drug percent dissolved between the test and reference products:

$$
f 2=50 * \log \left\{\left[1+(1 / n) \sum_{t=1}^{n}\left(R_{t}-T_{t}\right)^{2}\right]^{-0.5} * 100\right\}
$$

Where, $\mathrm{n}$ is the number of dissolution time points, Rt and $\mathrm{Tt}$ are the reference and test dissolution values (mean of at least 12 dosage units) at time $t$.

When the two dissolution profiles are identical, $\mathrm{f} 2=50$ $* \log (100)=100$, and when the dissolution of one product (test or reference) is completed before the other begins, $\mathrm{f} 2=50 * \log \{(1+1 / \mathrm{n} \Sigma(100) 2)-0.5 * 100\}=-$ 0.001 , which can be rounded to 0 . Thus the value of $f 2$ ranges from $0 *$ to 100 . Two dissolution profiles are considered 'similar' when the $\mathrm{f} 2$ value is between 50 and 100. Thus FDA recognizes the profiles to be similar when the two drug profiles differ only by a difference of $10 \%$. A higher f2 value indicates closeness between the two dissolution profiles.

Difference factor (f1) measures the percent error between two curves over all time points.

$$
f_{t}=\frac{\sum_{j=1}^{n}\left|R_{j}-T_{j}\right|}{\sum_{j=1}^{n} R_{j}} \times 100
$$

Where, $\mathrm{n}$ is the sampling number, $\mathrm{R}$ and $\mathrm{T}$ are the $\%$ dissolved of reference $\&$ test products at each time point j. The percent error is zero when the test and drug reference profiles are identical and increase proportionally with the dissimilarity between the two dissolution profiles. It is generally accepted that values of $\mathrm{f} 1$ between 0 - 15 do not indicate dissimilarity.

\section{Stability Study ${ }^{13}$}

The purpose of stability testing is to provide evidence on how the quality of a drug substance or drug product varies with time under the influence of temperature, humidity, and light and to establish a retest for the drug substance or a shelf life for the drug product and recommended storage conditions. The storage conditions used for accelerated stability studies were accelerated condition $\left(40{ }^{\circ} \mathrm{C} \pm 2{ }^{\circ} \mathrm{C} / 75 \% \pm 5 \% \mathrm{RH}\right)$ and Room temperature $\left(30^{\circ} \mathrm{C} \pm 2^{\circ} \mathrm{C} / 65 \% \mathrm{RH} \pm 5 \%\right)$. Stability study was carried out for the most satisfactory formulations. Tablets of optimized formulation were striped packed and kept in humidity chamber for 1 month on above mention temperature.

\section{RESULTS AND DISCUSSION}

\section{Drug Excipients Compatibility Study by FT-IR}

The FTIR spectra of pure drug and mixture of drug with excipient are shown in Figure 1. From this it is clear that the characteristic peaks at $1696.21(\mathrm{C}=\mathrm{O}$ stretching), 
1602.74 ( $\mathrm{C}=\mathrm{C}$ stretching), 1312.17 (C-N stretching) 748.14 (aromatic $-\mathrm{CH}$ Stretching) $\mathrm{cm}^{-1}$ are present in both the pure drug and mixture of drug with excipient, without any change in their positions, indicating no chemical interaction between drug and excipients.

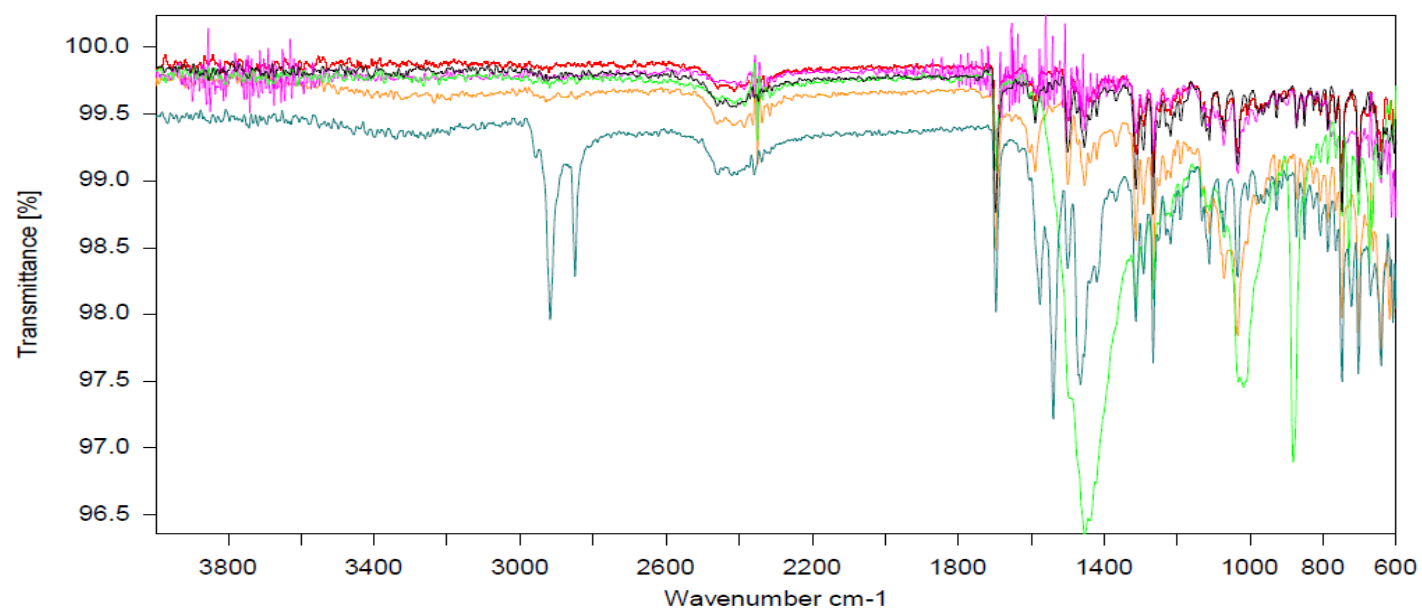

Figure 1: FT-IR Spectra of Donepezil Hydrochloride and all Excipient

\section{Pre-compression Evaluation of Powder Blend of Batches D1 to D9}

Granules prepared for compression of matrix tablets were evaluated for their flow properties, the results were shown in Table 4. Bulk density ranged from $0.572 \pm$ 0.041 to $0.632 \pm 0.025 \mathrm{gm} / \mathrm{ml}$, tapped density ranged from $0.667 \pm 0.049$ to $0.739 \pm 0.038 \mathrm{gm} / \mathrm{ml}$, Carr's index ranged from $12.50 \pm 1.25 \%$ to $14.74 \pm 1.88 \%$, Hausner's ratio ranged from $1.14 \pm 0.17$ to $1.17 \pm 0.69$ whereas Angle of repose ranged from $24.15 \pm 2.27$ to $27.75 \pm 2.28$. All these results indicated that, the powder blends possess excellent to good flowability and compressibility properties.

Table 4: Pre-Compression Evaluations of Design Batches D1 to D9

\begin{tabular}{|c|c|c|c|c|c|}
\hline $\begin{array}{c}\text { Batch } \\
\text { Code }\end{array}$ & $\begin{array}{c}\text { Bulk density } \\
(\mathbf{g m} / \mathbf{m l})\end{array}$ & $\begin{array}{c}\text { Tapped density } \\
\mathbf{( g m} / \mathbf{m l})\end{array}$ & $\begin{array}{c}\text { Compressibility } \\
\text { index } \\
(\mathbf{\%})\end{array}$ & Hausner's ratio & $\begin{array}{c}\text { Angle of repose } \\
(\boldsymbol{\theta})\end{array}$ \\
\hline D1 & $0.588 \pm 0.031$ & $0.689 \pm 0.024$ & $14.70 \pm 1.30$ & $1.17 \pm 0.69$ & $27.75 \pm 2.28$ \\
\hline D2 & $0.579 \pm 0.039$ & $0.669 \pm 0.031$ & $13.45 \pm 1.24$ & $1.15 \pm 0.21$ & $25.46 \pm 1.43$ \\
\hline D3 & $0.584 \pm 0.032$ & $0.675 \pm 0.028$ & $13.48 \pm 1.21$ & $1.15 \pm 0.25$ & $26.56 \pm 1.31$ \\
\hline D4 & $0.630 \pm 0.044$ & $0.739 \pm 0.038$ & $14.74 \pm 1.88$ & $1.17 \pm 0.27$ & $24.15 \pm 2.27$ \\
\hline D5 & $0.575 \pm 0.053$ & $0.667 \pm 0.049$ & $13.79 \pm 1.27$ & $1.16 \pm 0.05$ & $27.34 \pm 1.25$ \\
\hline D6 & $0.625 \pm 0.045$ & $0.714 \pm 0.042$ & $12.50 \pm 1.25$ & $1.14 \pm 0.17$ & $25.32 \pm 1.25$ \\
\hline D7 & $0.594 \pm 0.032$ & $0.691 \pm 0.028$ & $14.03 \pm 1.20$ & $1.16 \pm 0.21$ & $25.30 \pm 2.15$ \\
\hline D8 & $0.632 \pm 0.025$ & $0.726 \pm 0.021$ & $12.94 \pm 1.26$ & $1.14 \pm 0.57$ & $24.30 \pm 1.15$ \\
\hline D9 & $0.572 \pm 0.041$ & $0.668 \pm 0.036$ & $14.43 \pm 1.29$ & $1.16 \pm 0.35$ & $25.82 \pm 2.52$ \\
\hline
\end{tabular}

\section{Post Compression Evaluation of Batches D1 to D9}

The tablets from all the batches were evaluated for various physical parameters before proceeding further. Table 5 includes the values (mean \pm SD) of weight variation, hardness, thickness, friability and \% drug content of batches prepared using different combinations of functional excipients. Weight of the tablets in all the 9 batches varied between $249.26 \pm 0.47$ to $251.24 \pm$ $0.32 \mathrm{mg}$. All the formulated (D1 to D9) tablets passed weight variation test as the $\%$ weight variation was within the pharmacopoeial limits of $\pm 5 \%$ of the weight.
Diameter of all tablets was in the ranged from $7.97 \pm 0.002 \mathrm{~mm}$ to $7.99 \pm 0.004 \mathrm{~mm}$. Thickness of all tablets was in the range between $3.20 \pm 0.037 \mathrm{~mm}$ to $3.62 \pm 0.028 \mathrm{~mm}$. Hardness of tablets was in range between $5.11 \pm 0.023$ to $5.91 \pm 0.031 \mathrm{~kg} / \mathrm{cm}^{2}$. Friability was in range between $0.30 \pm 0.04$ to $0.58 \pm 0.45 \%$. Friability values were less than $1 \%$ in all cases which shows good mechanical strength at the time of handling and transports. Drug content of all tablets was found in the range between $98.65 \pm 2.20$ to $99.82 \pm 1.32 \%$. Thus, all the physical parameters of the compressed tablets complies the standards. 
Table 5: Post-Compression Evaluation Parameters of Full Factorial Design Batches

\begin{tabular}{|c|c|c|c|c|c|c|}
\hline $\begin{array}{c}\text { Batch } \\
\text { Code }\end{array}$ & $\begin{array}{c}\text { Weight } \\
\text { variation } \\
(\mathbf{n = 2 0})\end{array}$ & $\begin{array}{c}\text { Diameter } \\
(\mathbf{n = 5})\end{array}$ & $\begin{array}{c}\text { Thickness } \\
(\mathbf{m m}) \\
(\mathbf{n = 5})\end{array}$ & $\begin{array}{c}\text { Hardness } \\
\left(\mathbf{k g} / \mathbf{c m}^{2}\right) \\
(\mathbf{n = 5})\end{array}$ & $\begin{array}{c}\text { \% Friability } \\
(\mathbf{n = 5})\end{array}$ & $\begin{array}{c}\text { \% Drug } \\
\text { Content } \\
(\mathbf{n = 1 0})\end{array}$ \\
\hline D1 & Pass & $7.99 \pm 0.002$ & $3.28 \pm 0.015$ & $5.91 \pm 0.031$ & $0.46 \pm 0.17$ & $99.21 \pm 1.30$ \\
\hline D2 & Pass & $7.98 \pm 0.003$ & $3.62 \pm 0.028$ & $5.49 \pm 0.014$ & $0.47 \pm 0.32$ & $98.66 \pm 1.87$ \\
\hline D3 & Pass & $7.99 \pm 0.004$ & $3.37 \pm 0.035$ & $5.11 \pm 0.023$ & $0.58 \pm 0.45$ & $99.07 \pm 0.71$ \\
\hline D4 & Pass & $7.99 \pm 0.003$ & $3.42 \pm 0.032$ & $5.68 \pm 0.091$ & $0.30 \pm 0.45$ & $99.52 \pm 1.42$ \\
\hline D5 & Pass & $7.97 \pm 0.002$ & $3.37 \pm 0.054$ & $5.75 \pm 0.072$ & $0.50 \pm 0.25$ & $99.33 \pm 1.52$ \\
\hline D6 & Pass & $7.98 \pm 0.002$ & $3.28 \pm 0.075$ & $5.82 \pm 0.055$ & $0.58 \pm 0.03$ & $98.65 \pm 2.20$ \\
\hline D7 & Pass & $7.98 \pm 0.004$ & $3.45 \pm 0.047$ & $5.70 \pm 0.058$ & $0.45 \pm 0.15$ & $99.05 \pm 1.15$ \\
\hline D8 & Pass & $7.99 \pm 0.004$ & $3.60 \pm 0.041$ & $5.54 \pm 0.039$ & $0.30 \pm 0.04$ & $99.82 \pm 1.32$ \\
\hline D9 & Pass & $7.99 \pm 0.001$ & $3.20 \pm 0.037$ & $5.41 \pm 0.015$ & $0.52 \pm 0.05$ & $99.1 \pm 0.32$ \\
\hline
\end{tabular}

All values are expressed as mean \pm standard deviation

\section{In vitro Drug Release Study of Batches D1 to D9}

Batch D1 to D9 were developed using different concentration of Guar Gum $(40,50 \& 60 \mathrm{mg})$ and Xanthan gum $(40,50 \& 60 \mathrm{mg})$. Results of \% CDR study are shown in Figure 2. From the figure, it was observed that as the concentration of polymers Guar gum and Xanthan gum increases, amount of drug release decreases. Results exhibited that batch D1 containing $40 \mathrm{mg}$ of guar gum and $40 \mathrm{mg}$ of xanthan gum have shown better drug release $(99.74 \%)$ compared to other batches and it was similar to marketed product ALZIL SR23. Further this batch fulfills drug release as per the requirement at $2 \mathrm{hr}$ and $12 \mathrm{hr}$. So, batch D1 was considered as optimized batch among all formulated batches on the basis of drug release.

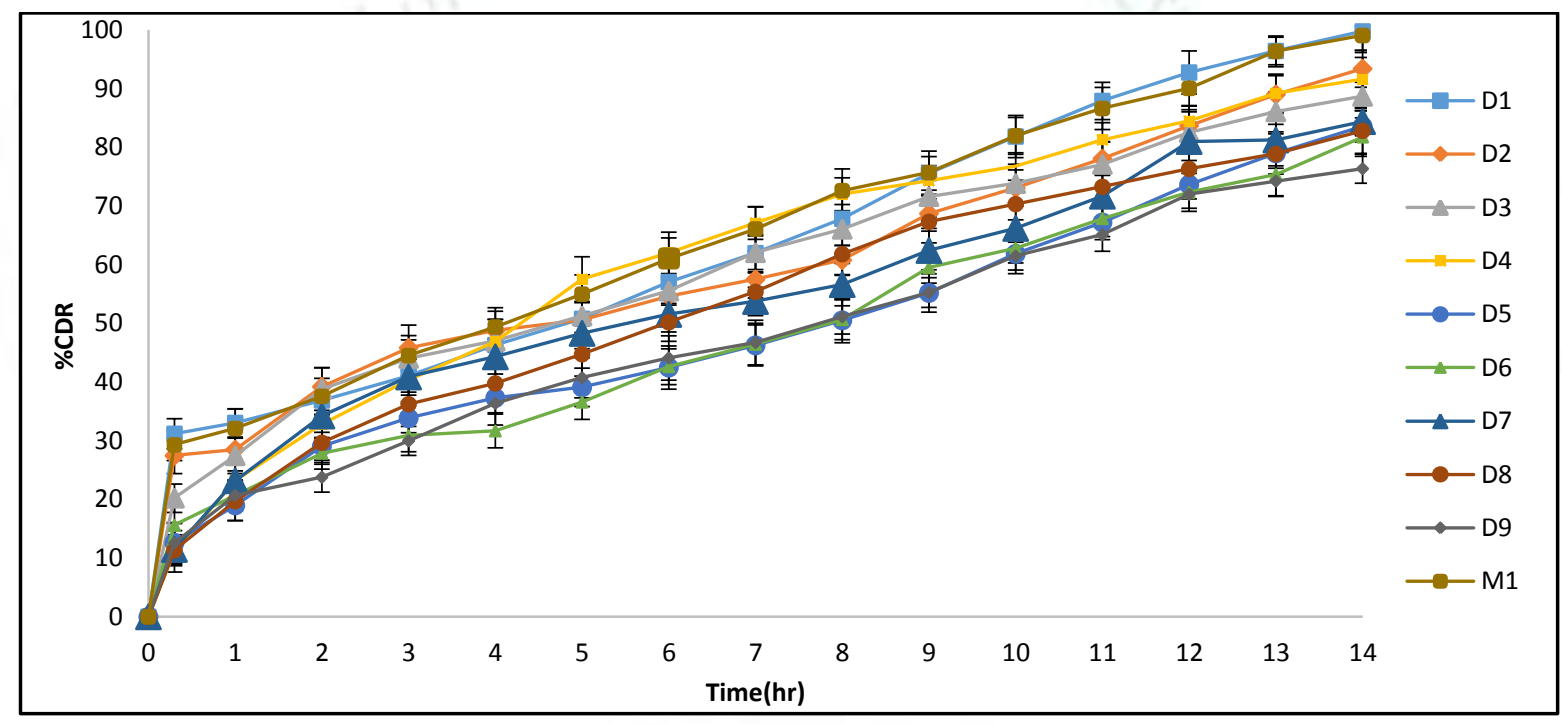

Figure 2: Cumulative \% Drug Release Study of D1 to D9 Batches

\section{Statistical Analysis}

Preliminary investigations of the process parameters revealed that factors concentration of Guar gum $\left(\mathrm{X}_{1}\right)$ and concentration of Xanthan gum $\left(\mathrm{X}_{2}\right)$ highly influenced the rate of in vitro dissolution and, hence, were used for further systematic studies.

\section{Effect of Polymers on \% CDR at $2 \mathrm{hr}$}

Mathematical relationships generated for the studied response variables concentration of Guar gum $\left(\mathrm{X}_{1}\right)$ \& concentration of Xanthan gum $\left(\mathrm{X}_{2}\right)$ for $\% \mathrm{CDR}$ at $2 \mathrm{hr}$ $\left(\mathrm{Y}_{1}\right)$ is as follows:

$Y_{1}=30.07-2.24 X_{1}-4.54 X_{2}-3.09 X_{1} X_{2}-0.2567 X_{1}^{2}+$ $3.85 X_{2}{ }^{2}, R^{2}=0.9884$
The high values of correlation coefficients for \%CDR at $2 \mathrm{hr}$ indicate a good fit. The polynomial equations can be used to draw conclusions after considering the magnitude of coefficient and the mathematical sign it carries, i.e positive or negative. Multiple linear regression analysis revealed that coefficient $b_{1}$ and $b_{2}$ is negative. This indicates that as the concentration of polymer decreases, \%CDR increases. Low levels of $\mathrm{X}_{1}$ and of $\mathrm{X}_{2}$ were found to be favorable conditions for obtaining better dissolution. Table 6 shows the results of analysis of variance (ANOVA), which was performed to identify insignificant factors. The coefficients $b_{1}, b_{2}, b_{12}$ and $b_{2}{ }^{2}$ were found to be significant at $P$ is less than 0.05 and thus, were retained in the reduced model equation.

$Y_{1}=30.07-2.24 X_{1}-4.54 X_{2}-3.09 X_{1} X_{2}+3.85 X_{2}^{2}$, $\mathbf{R}^{2}=\mathbf{0 . 9 8 7 8}$ 
Table 6: ANOVA Response Surface Quadratic Model for \%CDR at 2hr

\begin{tabular}{|c|c|c|c|c|c|}
\hline Source & SS & Df & MS & F Value & p-value prob > F \\
\hline Model & 221.77 & 5 & 44.35 & 51.30 & 0.0042 \\
\hline $\mathbf{X}_{\mathbf{1}}$ & 30.02 & 1 & 30.02 & 34.72 & 0.0098 \\
\hline $\mathbf{X}_{\mathbf{2}}$ & 123.67 & 1 & 123.67 & 143.04 & 0.0013 \\
\hline $\mathbf{X}_{\mathbf{1}} \mathbf{X}_{\mathbf{2}}$ & 38.25 & 1 & 38.25 & 44.24 & 0.0069 \\
\hline $\mathbf{X}_{\mathbf{1}}^{\mathbf{2}}$ & 0.1318 & 1 & 0.1318 & 0.1524 & 0.7223 \\
\hline $\mathbf{X}_{\mathbf{2}}^{\mathbf{2}}$ & 29.70 & 1 & 29.70 & 34.35 & 0.0099 \\
\hline Residual & 2.59 & 3 & 0.8646 & - & - \\
\hline Cor Total & 224.36 & 8 & - & - & - \\
\hline
\end{tabular}

The 2D and 3D response surface for responses $\mathrm{Y}_{1}$ was also drawn to study the effect of variables on response and it was shown in Figure 3.

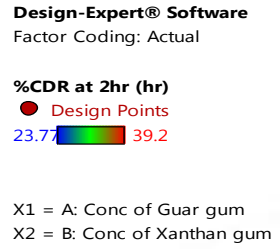

$\mathrm{X} 2=\mathrm{B}$ : Conc of Xanthan gum

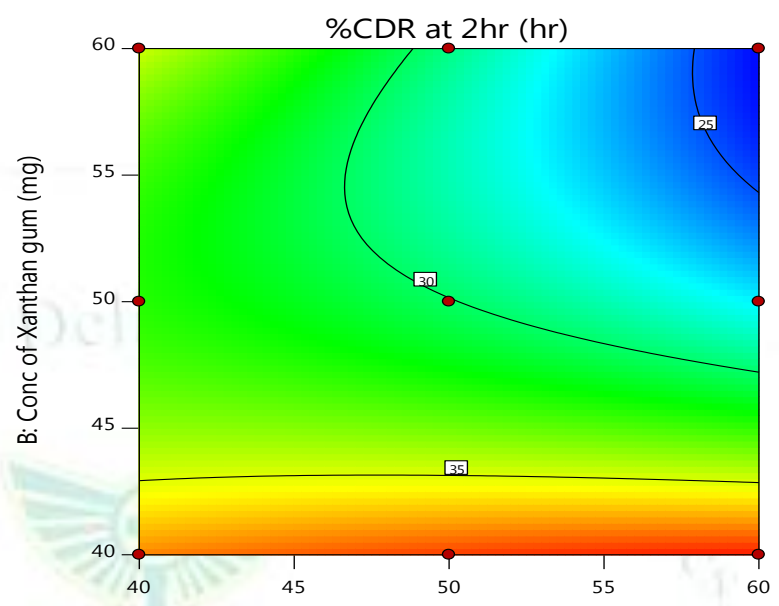

A: Conc of Guar gum (mg)

Design-Expert $₫$ Software

Factor Coding: Actual

\%CDR at $2 \mathrm{hr}$ (hr)

- Design points above predicted value Design points below predicted value

39.2

$\mathrm{X} 1=\mathrm{A}:$ Conc of Guar gum $X_{2}=B$ : Conc of Xanthan gum

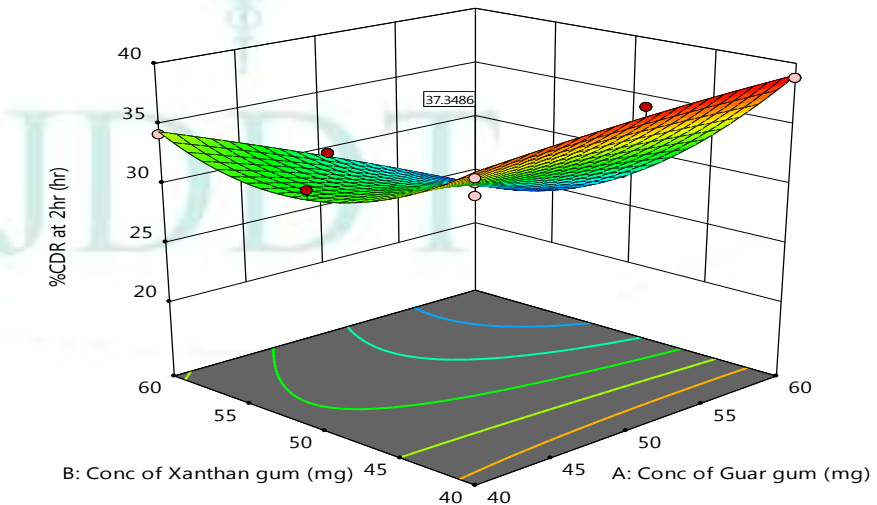

Figure 3: 2D and 3D Curve Concentration of Guar gum $\left(\mathrm{X}_{1}\right) \&$ Xanthan gum $\left(\mathrm{X}_{2}\right)$ for \% CDR at $2 \mathrm{hr}\left(\mathrm{Y}_{1}\right)$

\section{Effect of Polymers on \% CDR at 12hr}

Mathematical relationships generated for the studied response variables concentration of Guar gum $\left(\mathrm{X}_{1}\right)$ \& concentration of Xanthan gum $\left(\mathrm{X}_{2}\right)$ for $\% \mathrm{CDR}$ at $12 \mathrm{hr}$ $\left(\mathrm{Y}_{2}\right)$ is as follows:

$Y_{2}=74.83-5.23 X_{1}-4.94 X_{2}-0.3075 X_{1} X_{2}+2.96 X_{1}^{2}+$ $4.55 X_{2}^{2}, R^{2}=0.9734$

The high values of correlation coefficients for \%CDR at $2 \mathrm{hr}$ indicate a good fit. The polynomial equations can be used to draw conclusions after considering the magnitude of coefficient and the mathematical sign it carries, i.e positive or negative. Multiple linear regression analysis revealed that coefficient $b_{1}$ and $b_{2}$ is negative. This indicates that as the concentration of polymer decreases, \%CDR increases. Low levels of $\mathrm{X}_{1}$ and of $\mathrm{X}_{2}$ were found to be favorable conditions for obtaining better dissolution. Table 7 shows the results of analysis of variance (ANOVA), which was performed to identify insignificant factors. The coefficients $b_{1}, b_{2}$ and $\mathrm{b}_{2}{ }^{2}$ were found to be significant at $\mathrm{P}$ is less than 0.05 and thus, were retained in the reduced model equation.

$Y_{2}=74.83-5.23 X_{1}-4.94 X_{2}+4.55 X_{2}{ }^{2}, R^{2}=0.9262$ 
Table 7: ANOVA Response Surface Quadratic Model for \%CDR at $12 \mathrm{hr}$

\begin{tabular}{|c|c|c|c|c|c|}
\hline Source & SS & Df & MS & F Value & p-value prob > F \\
\hline Model & 370.14 & 5 & 74.03 & 21.98 & 0.0144 \\
\hline $\mathbf{X}_{\mathbf{1}}$ & 164.12 & 1 & 164.12 & 48.74 & 0.0060 \\
\hline $\mathbf{X}_{\mathbf{2}}$ & 146.62 & 1 & 146.62 & 43.54 & 0.0071 \\
\hline $\mathbf{X}_{\mathbf{1}} \mathbf{X}_{\mathbf{2}}$ & 0.3782 & 1 & 0.3782 & 0.1123 & 0.7596 \\
\hline $\mathbf{X}_{\mathbf{1}}{ }^{2}$ & 17.56 & 1 & 17.56 & 5.22 & 0.1066 \\
\hline $\mathbf{X}_{\mathbf{2}}{ }^{2}$ & 41.47 & 1 & 41.47 & 12.31 & 0.0392 \\
\hline Residual & 10.10 & 3 & 3.37 & - & - \\
\hline Cor Total & 380.25 & 8 & - & - & - \\
\hline
\end{tabular}

The 2D and 3D response surface for responses $\mathrm{Y}_{2}$ was also drawn to study the effect of variables on response and it was shown in Figure 4.

Design-Expert ${ }^{\circledR}$ Software

Factor Coding: Actual

\section{\%CDR at $12 \mathrm{hr}(\mathrm{hr})$}

- Design Points

$71.98 \square 92.74$

$\mathrm{X} 1=\mathrm{A}:$ Conc of Guar gum $\mathrm{X} 2=\mathrm{B}$ : Conc of Xanthan gum

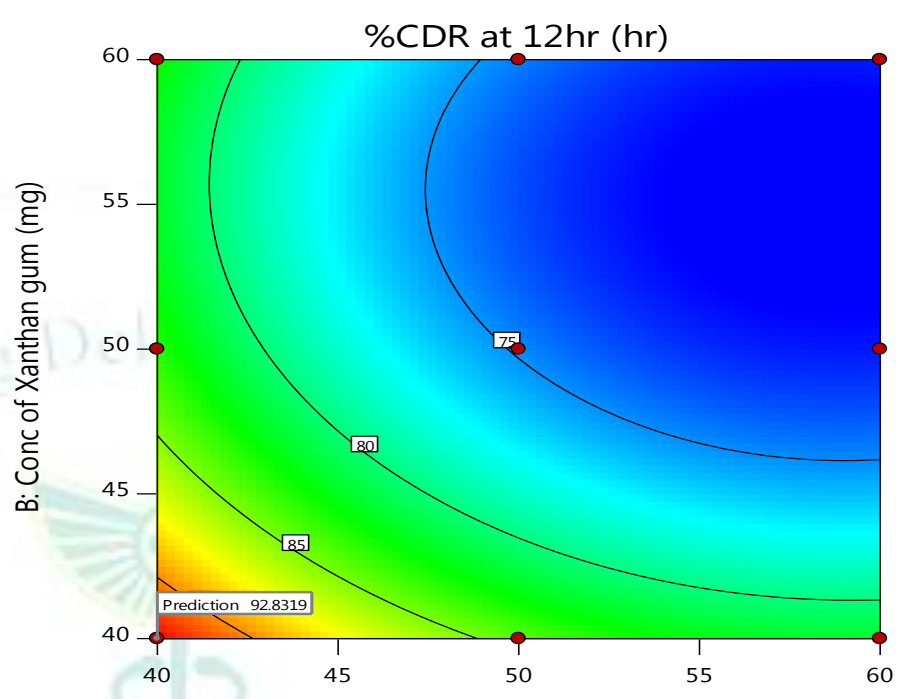

A: Conc of Guar gum (mg)

Design-Expert ${ }^{\circledR}$ Software

Factor Coding: Actual

\%CDR at 12hr (hr)

Design points above predicted value

Design points below predicted value

$71.98 \square 92.74$

$\mathrm{X} 1=\mathrm{A}$ : Conc of Guar gum

$\mathrm{X} 2=\mathrm{B}$ : Conc of Xanthan gum

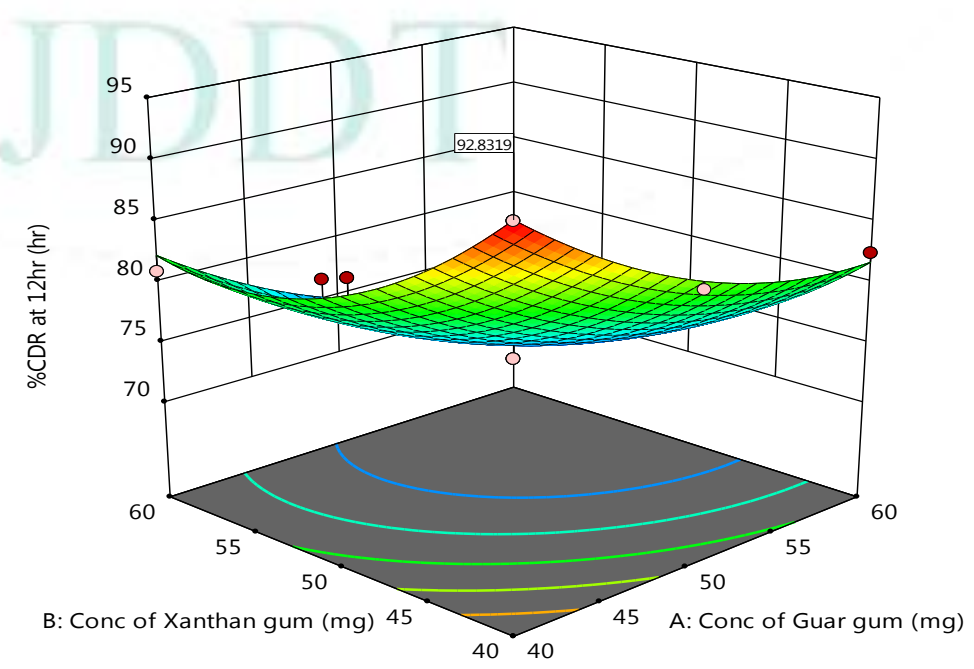

Figure 4: 2D and 3D Curve Concentration of Guar gum $\left(\mathrm{X}_{1}\right)$ \& Xanthan gum $\left(\mathrm{X}_{2}\right)$ for \%CDR at 12hr $\left(\mathrm{Y}_{2}\right)$

\section{Check Point Analysis}

Three check point batches were prepared and evaluated for $\% \mathrm{CDR}$ at $2 \mathrm{hr}$ and $\% \mathrm{CDR}$ at $12 \mathrm{hr}$ as shown in table
8. When measured \% CDR values were compared with predicted $\% \mathrm{CDR}$, the differences were found to be not significant. Thus, it can be concluded that the obtained mathematical equation is valid for predicted values. 
Table 8: Checkpoint Batches with Predicted and Measured Value of \%CDR at $2 \mathrm{hr}$ and at $12 \mathrm{hr}$

\begin{tabular}{|c|c|c|c|c|c|c|}
\hline \multirow{2}{*}{ Batch Code } & \multirow{2}{*}{$\mathbf{X}_{\mathbf{1}}$} & \multirow{2}{*}{$\mathbf{X}_{\mathbf{2}}$} & \multicolumn{2}{|c|}{$\begin{array}{c}\text { \%CDR at 2hr } \\
\left(\mathbf{Y}_{\mathbf{1}}\right)\end{array}$} & \multicolumn{2}{c|}{$\begin{array}{c}\text { \% CDR at 12hr } \\
\left(\mathbf{Y}_{\mathbf{2}}\right)\end{array}$} \\
\cline { 4 - 7 } & & & Measured & Predicted & Measured & Predicted \\
\hline D10 & 0 & 0.5 & 28.31 & 28.76 & 73.48 & 73.53 \\
\hline D11 & 0.5 & 1 & 26.50 & 26.65 & 72.36 & 72.41 \\
\hline D12 & 1 & 0.5 & 24.51 & 24.42 & 71.02 & 71.07 \\
\hline
\end{tabular}

\section{Optimization of Formulation}

The overlay plot of responses generates an optimized area as per desired criteria (Figure 5). This was the most important part of the response surface methodology. The formulation of the drug which released the drug in controlled and complete manner was selected for optimum formulation. After studying the effect of the independent variables on the responses, the levels of these variables that give the optimum response were determined. The optimum formulation was selected based on the criteria of attaining complete and controlled drug release. Batch D1 having $40 \mathrm{mg}$ of Guar gum and $40 \mathrm{mg}$ of Xanthan gum fulfilled maximum requisites of an optimum formulation because of better regulation of release rate. The said formulation released $37.35 \%$ of drug in $2 \mathrm{hr}$. and $92.84 \%$ in $12 \mathrm{hr}$., however, the drug completely got released i.e. $99.74 \%$ in 14 hours, which were in close agreement with the theoretical values.
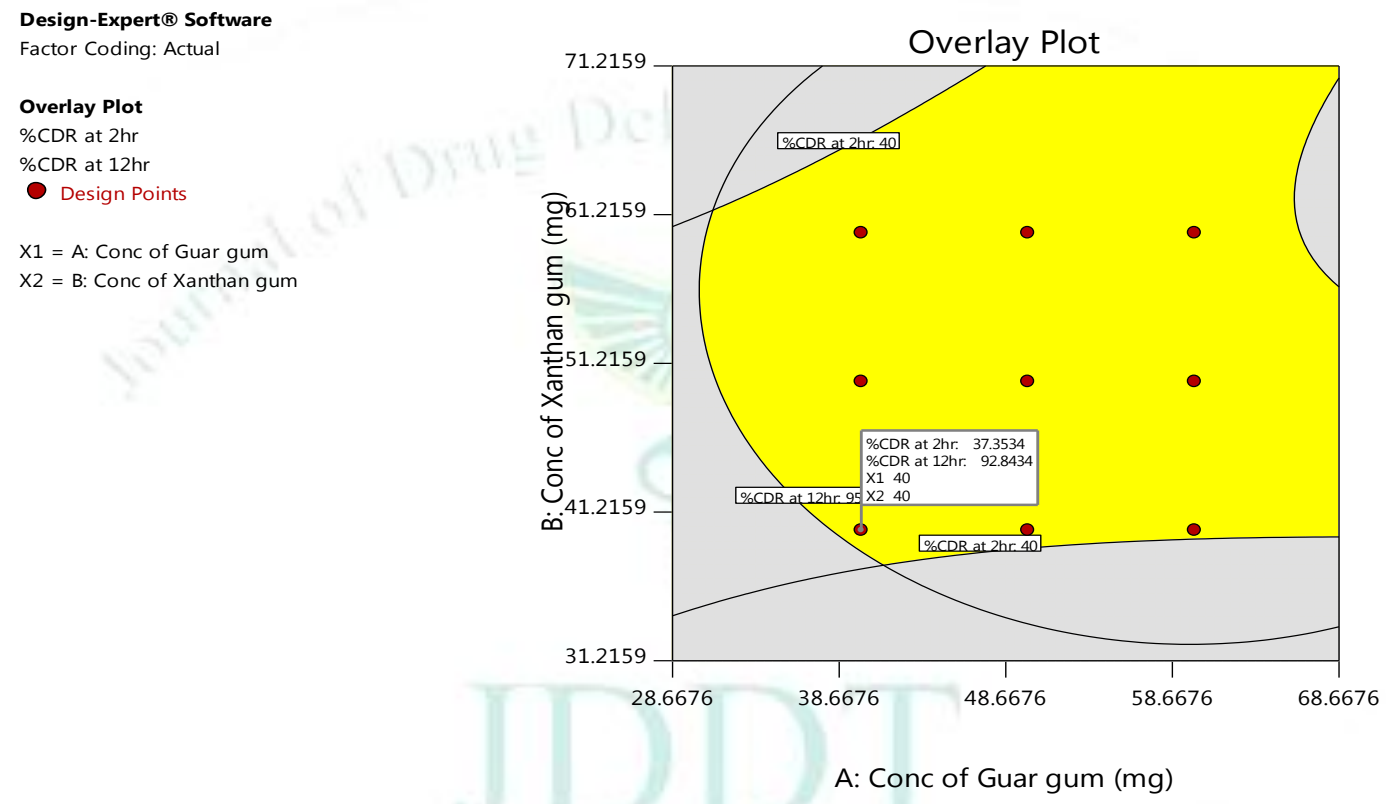

Figure 5: Overlay Plot of Batch D1

\section{Drug Release Kinetic Study}

In order to examine the kinetic of drug release from prepared sustained release tablets, the dissolution data of optimized formulation D1 was fitted into different kinetic models i.e. Zero order, First order, Higuchi model, Hixson- Crowell and Korsemeyer-Peppas model (Figure 6 to 10). The criteria for the selection of most suitable model were value of regression coefficient $\left(\mathrm{R}^{2}\right)$ nearer to 1 , smallest values of Residual sum of squares
(SSR) and Akaike Information Criteria (AIC). Table 9 shows the data obtained. The optimized formulation fitted well into Korsemeyer-Peppas, it was confirming the desired release profile. The calculated $\mathrm{R}^{2}$ value for Korsemeyer-Peppas was 0.9517. According to Korsemeyer-Peppas equation, the release exponent " $n$ " value is between $0.45<\mathrm{n}<0.89$, which indicates that drug release is non-fickian diffusion type and states that release followed the diffusion controlled mechanism.

Table 9: Fitting of Release Profile of Optimized Formulation to Kinetic Models

\begin{tabular}{|c|c|c|c|c|c|c|}
\hline \multirow{2}{*}{ Batch } & \multirow{2}{*}{ Model } & \multicolumn{5}{|c|}{ Parameters Used } \\
\hline & & $\mathbf{R}^{2}$ & $\mathbf{R}$ & $\mathbf{K}$ & SSR & AIC \\
\hline \multirow{5}{*}{ D1 } & Zero-order & 0.7592 & 0.9743 & 8.102 & 2858.1321 & 129.326 \\
\hline & First-order & 0.8785 & 0.9532 & 0.171 & 1442.0205 & 118.380 \\
\hline & Higuchi & 0.9317 & 0.9770 & 25.584 & 574.4741 & 105.627 \\
\hline & Korsemeyer-Peppas & 0.9517 & 0.9772 & $\begin{array}{c}25.378 \\
n=0.504\end{array}$ & 573.2614 & 103.621 \\
\hline & Hixson Crowell & 0.8755 & 0.9639 & 0.045 & 1477.8248 & 118.773 \\
\hline
\end{tabular}




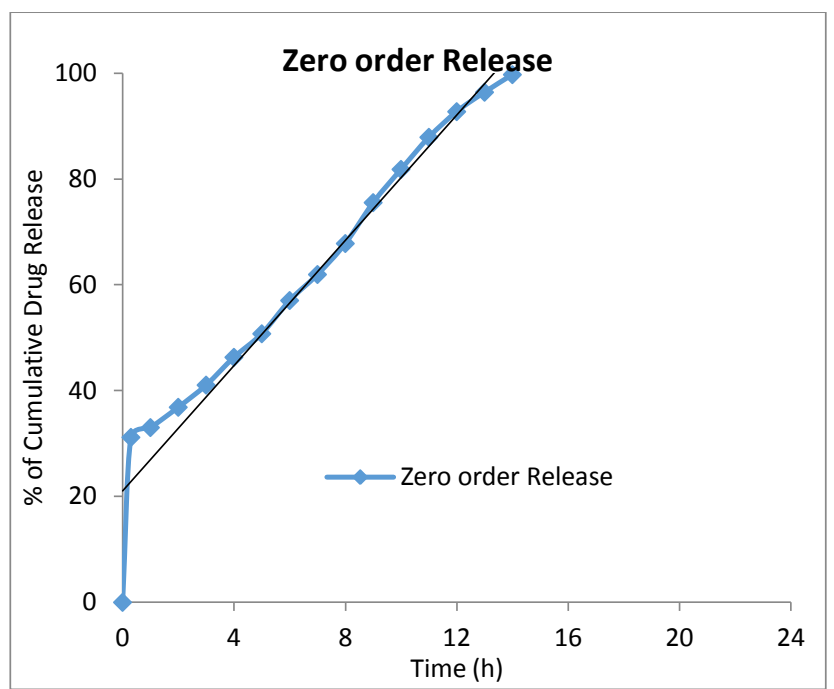

Figure 6: Zero-order Release Kinetic Model

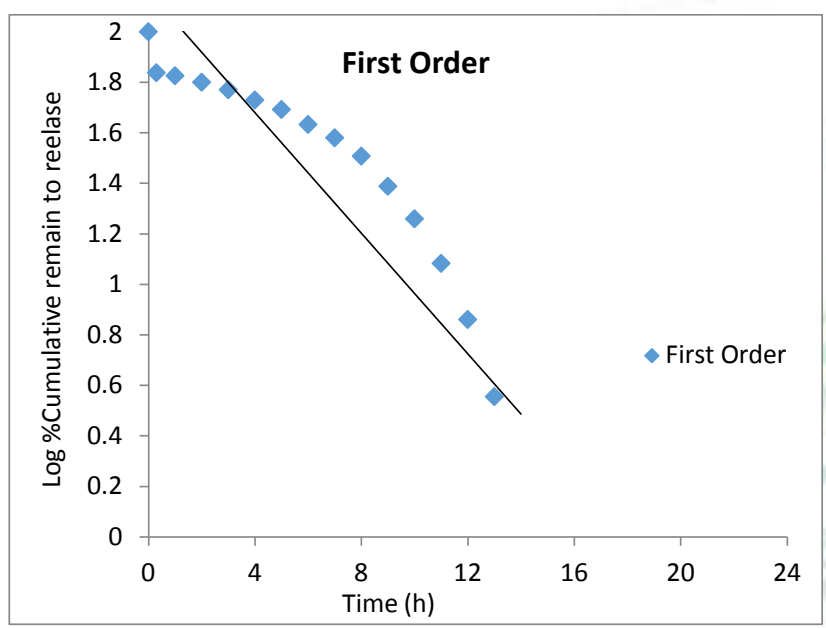

Figure 7: First-order Kinetic Model

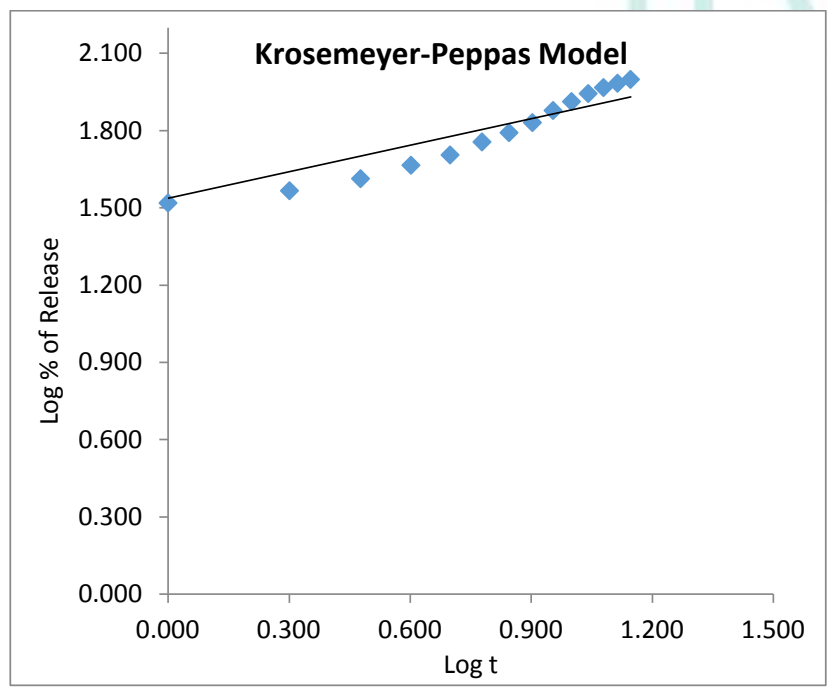

Figure 8: Krosemeyer-Peppas Kinetic Model

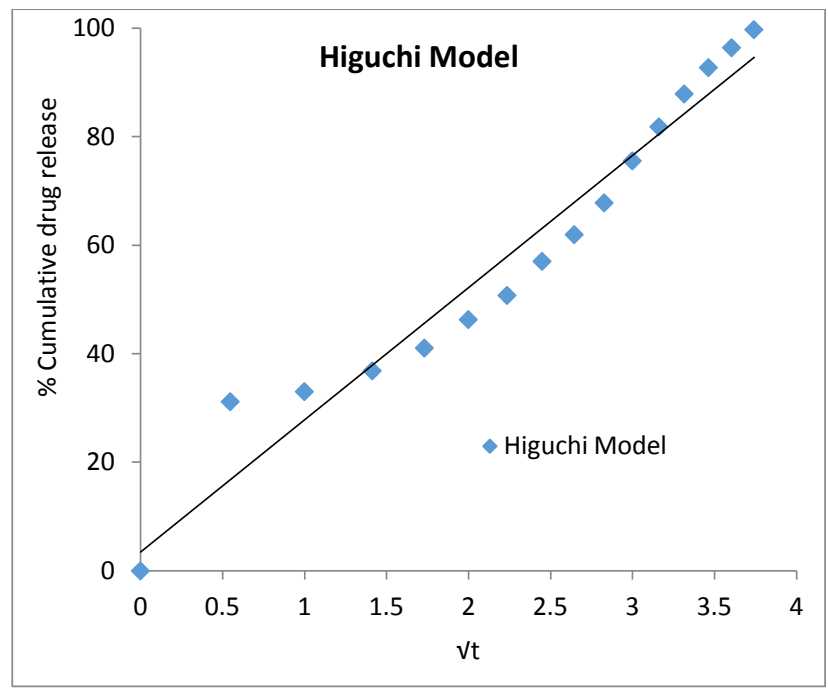

Figure 9: Higuchi Kinetic Model

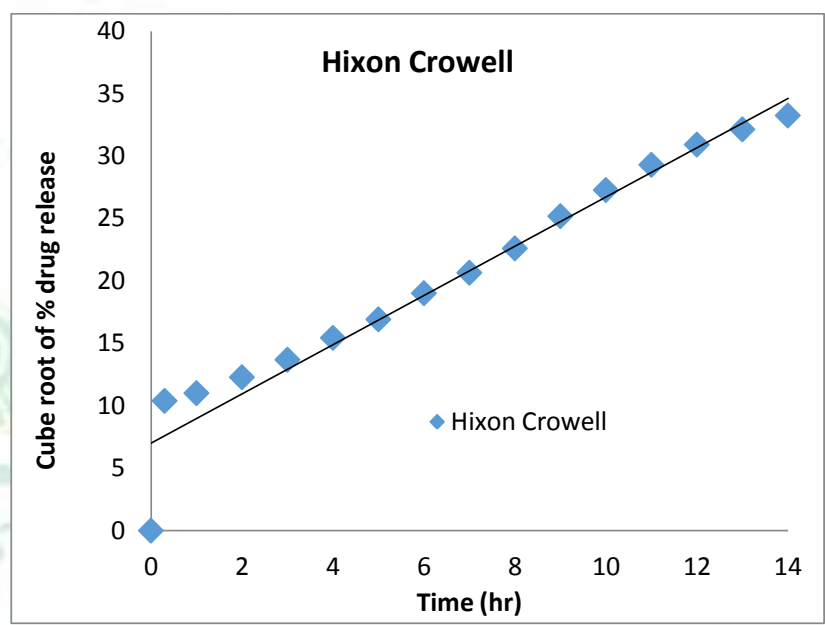

Figure 10: Hixon Crowell Kinetic Model

\section{Similarity and Dissimilarity Study}

Similarity factor (F2) and dissimilarity factor (F1) were calculated for optimized batch D1 and values were found to be 76.80 and 1.73 respectively. F2 value was within 50 to 100 and $F 1$ value was within 0 to 15 . This indicates that sustained release matrix tablets prepared using guar gum and xanthan gum (Batch D1) is similar to the marketed tablet formulation (ALZIL SR-23).

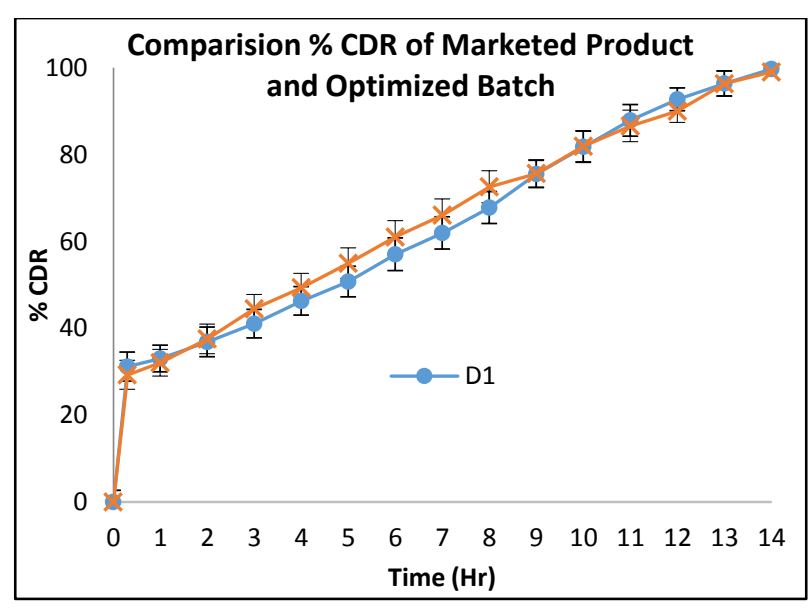

Figure 11: Comparison \% CDR of Optimized Batch with Marketed Product 
Comparison \%CDR of marketed product and optimized formulation was presented in Figure 11.

\section{Stability Study}

Stability study of sustained release matrix tablet of Donepezil hydrochloride (batch D1) was carried out for
1 month at specified condition. All data are mentioned in table 10. The stability studies of the optimized formulation (batch D1) shown no significant changes in the $\%$ drug content and $\%$ drug release at $14 \mathrm{hr}$. when stored at $40 \pm 2^{\circ} \mathrm{C} / 75 \pm 5 \% \mathrm{RH}$.

Table 10: Stability Study of Optimized Formulation (D1) carried out at $40 \pm 2{ }^{\circ} \mathrm{C} / 75 \pm 5 \% \mathrm{RH}$

\begin{tabular}{|c|c|c|}
\hline No. of Months & $\begin{array}{c}\text { \%Drug Content } \\
(\mathbf{n = 3})\end{array}$ & $\begin{array}{c}\text { \% Drug release at 14 hr. } \\
(\mathbf{n}=\mathbf{3})\end{array}$ \\
\hline 0 & $99.21 \pm 1.30$ & $99.74 \pm 3.24$ \\
\hline 1 & $99.36 \pm 1.47$ & $99.49 \pm 3.72$ \\
\hline
\end{tabular}

All values are expressed as mean \pm standard deviation, $n=3$

\section{CONCLUSION}

The matrix type of tablets is potential to be an effective sustained release drug delivery system over a prolong period of time. The type and level of polymer used are important factors that can affect the drug release and also the physicochemical properties of this sustained release matrix tablets. $3^{2}$ full factorial design was applied to achieve controlled drug release up to $14 \mathrm{hr}$. Among all the developed formulations, D1 formulation which contained the mixture of two polymers Guar gum and Xanthan gum sustained drug release for $14 \mathrm{hr}$. when compared with other formulations and also similar as marketed formulation. So, D1 was selected as the best formulation. The drug release kinetics follows Korsemeyer-peppas and the mechanism was found to be non Fickian and shows continuous and uniform drug release for extended period of time. The stability studies were carried out according to ICH guideline which indicates that the selected formulation was stable. From the economical point of view, it may be beneficial for the local pharmaceutical firms to adopt such simple technologies for the preparation of sustained release product.

\section{ACKNOWLEDGEMENT}

We express our sincere thanks to Dr. M. M. Patel, Director and Shastri Shri Purushottam Charan Dasji, Managing Trustee of Shree Swaminarayan Sanskar Pharmacy College, Zundal, Gandhinagar, Gujarat for providing excellent facilities for research work.

\section{REFERENCES}

1. Gedar S, Kataria M, Bilandi A, "Sustained Release Matrix Tablet of Glipizide" International Journal of Pharmaceutical Sciences and Research, 2014; 4(1):12-17.

2. Mandhar P, Joshi G, "Development of Sustained Release Drug Delivery System: A Review", Asian Pacific Journal of Health Sciences, 2015; 2(1):179-185.

3. Sweetman SC, Martindale: the complete drug reference, 2009.

4. Deepthi PR, Prasad V, Diwan P, "Preparation and In-Vitro Evaluation of Donepezil Hydrochloride Sustained Release Matrix Tablets Using Non-Gelling Polymer" IOSR Journal of Pharmacy and Biological Sciences, 2014; 9(5):83-91.

5. Tripathi AR, Patel KN, Patel PA, Nayak BS, Shah V, "Formulation and Evaluation of Bilayer Tablets Containing L-Arginine" International Journal for Pharmaceutical Research Scholars 2015; 4(1):1-18.

6. Patel KN, Mehta TA, "Formulation Design and Characterization of an Elementary Osmotic Pump Tablet of Flurbiprofen" PDA Journal of Pharmaceutical Science and Technology, 2014; 68:333-346.

7. Gangurde H, Chordiya M, Tamizharasi S, Senthilkumaran K, and Sivakumar T, " Formulation and Evaluation of Sustained Release Bioadhesive Tablets of Ofloxacin using $3^{2}$ Factorial Design" International Journal of Pharmaceutical Investigation, 2011; 1(3):148-156.

8. Bankar A, Bankar V, Gaikwad P, and Pawar S, "Formulation Design and Optimization of Sustained Release Tablet of Ambroxol hydrochloride" International Journal of Drug Delivery, 2012; 375-385.

9. Patel J, Dhingani A, Dabhi M, Patel N, Raval M, Sheth N, "Design and Development of Sustained Release Microspheres of Quetiapine Fumarate using $3^{2}$ Full Factorial Design" Journal of Pharmacy Research, 2010; 3(12):28712875.

10. Shailender M, "Compression Physics of Pharmaceutical Powders: A Review" International Journal of Pharmaceutical Sciences and Research, 2012; 3(6):1580-1592.

11. Gupta DK, Sharma RD, Gupta R, Tyagi S, Sharma KK, Choudhary A. "Formulation and Evaluation of Orodispersible Tablets of Salbutamol Sulphate" International Journal of Pharmaceutical Sciences and Research, 2012;3(8):2675.

12. Costa P, Manuel J, "Modeling and Comparison of Dissolution Profiles" Journal of Pharmaceutical Sciences, 2000; 123-133.

13. ICH Guidelines Q1A (R2), Guidance for industry, stability testing of new drug substances and products, World Health Organization, WHO Technical Report Series, no. 953, 2009. 